\title{
Educação e envelhecimento: realidades da educação de jovens e adultos
}

\author{
Renato Xavier Coutinho", Juliana Maria Rodrigues", Marco Aurelio de Figueiredo Acosta**
}

\section{Resumo}

O presente estudo teve como objetivo analisar a participação dos idosos em programas de educação de jovens e adultos na cidade de Santa Maria/RS, com o intuito de identificar quais motivos levaram o idoso a voltar ou a começar estudar; conhecer como se sente o educando idoso; reconhecer a percepção dos professores de alunos idosos; e analisar a participação do idoso em sala de aula. Desenvolveu-se um estudo descritivo de cunho qualitativo, por meio de entrevistas e observações com os idosos e seus professores. Participaram do estudo quatro professores e 13 idosos. Por meio dos resultados, observou-se que os motivos que os levaram à escola são a busca da independência, da autonomia e da liberdade, condições que estão associadas ao ato de ler e escrever. A socialização também é um dos principais motivos que levou esses idosos a engajarem-se na EJA. Quanto aos professores, identificou-se que nenhum dos quatro entrevistados afirmou ter tido preparação específica sobre o envelhecimento, ou para trabalhar com pes- soas mais velhas, baseando sua prática na experiência pregressa. Portanto, destaca-se a importância de uma aproximação entre universidade e escola com o intuito de preparar esses professores para essa realidade. Assim, a participação efetiva do idoso na escola pode se constituir, num primeiro passo, para uma tomada de consciência de um ser que cresceu e desenvolveu-se como mero expectador de sua própria vida.

Palavras-chave: Educação. Envelhecimento. Escola.

\section{Introdução}

Com o crescente número de pessoas idosas, decorrente do processo de transição demográfica em que o Brasil vive, a promoção da qualidade de vida na velhice é assunto que vem sendo abordado por muitos estudiosos em diferentes áreas do conhecimento.

* Graduado em Educação Física, Doutor em Educação em Ciências pela UFSM, Professor do Instituto Federal Farroupilha Campus São Vicente do Sul. E-mail: renatocoutinho@msn.com.

** Graduada em Educação Física, Especialista em atividade física, desempenho motor e saúde.

*** Graduado em Educação Física, Doutor em Ciências do Movimento Humano pela Universidade Federal de Santa Maria, Coordenador do Núcleo Integrado de Estudos em Apoio à Terceira Idade - NIEATI/ UFSM.

$\rightarrow$ http://dx.doi.org/10.5335/rbceh.2014.3288

Recebido em: 01/07/2013. Aprovado em: 01/07/2014 
Segundo Santos e Sá (2000), a educação é um dos meios para vencer os desafios impostos aos idosos pela idade e pela sociedade, propiciando-lhes o aprendizado de novos conhecimentos e oportunidades para buscar seu bem-estar integral. O autor ainda afirma que por meio de uma educação continuada, têm-se possibilitado ao idoso a atualização, a aquisição de conhecimentos e a participação em atividades culturais, sociais, políticas e de lazer.

As oportunidades educacionais são apontadas como importantes antecedentes de ganhos evolutivos na velhice através da intensificação dos contatos sociais, das trocas de vivências e de conhecimentos e também do aperfeiçoamento pessoal (NERI; CACHIONI, 1999).

Alguns termos e expressões são utilizadas para definir a educação de idosos, entre eles a gerontologia educacional, que de acordo com Neri e Cachioni (1999) foi usada pela primeira vez na Universidade de Michigan, como título de um programa de doutorado, e abrange três áreas: a educação para os idosos, ou seja, programas educacionais voltados a atender às necessidades dos idosos, considerando suas características; a educação para a população em geral sobre a velhice e os idosos, programas educacionais que possibilitam à população mais jovem rever seus conceitos sobre a velhice e o seu próprio processo de envelhecimento; e a formação de recursos humanos para o trabalho com os idosos, que é a capacitação técnica de profissionais, para a prestação de serviços às pessoas idosas e a formação de pesquisadores.
Ainda, Neri e Cachioni (1999), em Glendenning no ano de 1989, propuseram uma nova subdivisão, uma área seria a gerontologia educacional, já descrita, e a outra seria a de Educação Gerontológica, com foco no ensino sobre a velhice e envelhecimento numa sociedade que envelhece, com a finalidade de preparar e atualizar para carreiras profissionais em Gerontologia, de preparar cuidadores informais e de oferecer à sociedade informações sobre a velhice, o envelhecimento e as necessidades dos idosos.

A expressão também usual na literatura internacional lifelong education, que pode ser traduzida como Educação Permanente, diz respeito à educação de adultos maduros e idosos, mas não se restringe a essa, nem a outro período particular do curso de vida.Segundo Palma e Cachioni (2002), uma educação permanente realmente dirigida às necessidades das sociedades modernas não pode definir-se em relação a um período particular da vida, mas deve permitir aprender ao longo de todo o curso de vida. A educação permanente significa uma exigência nova, de autonomia dinâmica dos indivíduos em uma sociedade em rápida transformação. Outro termo utilizado é gerontogogia ou gerontagogia. Segundo Palma e Cachioni (2002), a gerontagogia é situada como a disciplina das ciências da educação, e nessa busca-se o estudo da prática educativa não como parte desse processo de envelhecimento, mas como o ensino e a aprendizagem de pessoas diversas entre si relacionadas com um contexto e com uma vida pessoal e social, as quais 
tratam de progredir, visando o maior bem-estar possível.

Desse modo, o presente estudo tem como objetivo analisar a participação dos idosos em programas de educação de jovens e adultos na cidade de Santa Maria/RS, com o intuito de conhecer quais motivos levaram o idoso a voltar ou a começar estudar; conhecer como se sente o educando idoso, quais as maiores dificuldades, quais os benefícios e as mudanças sentidas por ele; conhecer a percepção dos professores de alunos idosos; analisar a participação do idoso em sala de aula, e verificar como se encontra o espaço-físico, a estrutura e o ambiente em que esses idosos estudam.

\section{Materiais e métodos}

Esse estudo é caracterizado segundo Chizzotti (2000) como uma pesquisa descritiva de cunho qualitativo, a qual seleciona intencionalmente sua amostra. O estudo teve como participantes idosos que estudam em escolas no programa de educação de jovens e adultos da cidade de Santa Maria/RS, assim como seus professores. Os critérios utilizados para definir as escolas participantes do estudo foram: a distribuição geográfica, uma escola representando cada região da cidade; e a escola com maior número de idosos matriculados. A partir desses critérios foram selecionadas quatro escolas, conforme a Tabela 1.

Tabela 1 - Escolas e turmas selecionadas para o estudo

\begin{tabular}{l|l|l|l}
\cline { 2 - 4 } & \multicolumn{1}{c|}{ Região } & \multicolumn{1}{c}{ Escola } & \multicolumn{1}{c}{ Turma participante } \\
\hline 1 & Norte & E. E. Básica Érico Veríssimo & Totalidade 1 \\
2 & Sul & E. E. E. Básica Irmão José Otão & Totalidade 1 \\
3 & Leste & E. M. E. F. Júlio do Canto & Etapa 1 \\
4 & Oeste & C. E. Tancredo Neves & Etapa 1 \\
\hline
\end{tabular}

Fonte: dados da pesquisa.

Em cada escola, foi selecionada a turma que continha o número mais significativo de idosos, na qual foram realizadas as entrevistas e as observações. Pretendeu-se entrevistar o maior número possível de idosos, e também foram participantes da amostra seus professores, por possuírem vínculo com os idosos, ajudando a fornecer informações para enriquecer o trabalho e alcançar o objetivo proposto.

Os instrumentos utilizados foram, primeiramente, observações partici- pantes durante as aulas, totalizando 16 observações, quatro em cada escola. Observações do espaço físico, com o objetivo de verificar como se encontra a estrutura da escola e o ambiente onde esses idosos estudam. Entrevista, com questões abertas, com 13 idosos matriculados e frequentes nas aulas. $\mathrm{E}$ também foram realizadas entrevistas, com questões abertas, com os professores de currículo, responsáveis pelas turmas, cada um representando uma escola de diferente região da cidade. Todos os instrumentos 
utilizados no estudo tiveram como base questões do estudo de Acosta (2007).

Inicialmente, foi realizado contato com a Secretaria Municipal de Educação (SMEd) e com a 8a Coordenadoria Regional de Educação ( $8^{\mathrm{a}} \mathrm{CRE}$ ) para mapear quais escolas de Santa Maria possuem o programa de Educação de Jovens e Adultos (EJA).

A partir disso, as escolas com EJA foram contatadas para verificar se tinham idosos matriculados. Aos coordenadores e/ou diretores das escolas selecionadas foi explanado o estudo, para a autorização de realização desse. Em seguida, foram definidas as turmas com maior número de idosos, para as observações e as entrevistas, que foram marcadas conforme a disponibilidade dos participantes. Por fim, foi entregue o termo de consentimento livre e esclarecido aos colaboradores da pesquisa, autorizando o uso das informações relatadas no estudo. O presente projeto foi aprovado pelo Comitê de Ética da Universidade Federal de Santa Maria, sob o número CAAE 0196.0.243.000-07.

\section{Resultados e discussão}

Uma limitação encontrada no início, ao conversar com supervisores e diretores das escolas, foi em relação à falta de um entendimento para os termos "idosos" e "terceira idade", pois há ainda pouco esclarecimento a cerca desses, gerando compreensões distintas do que vem a ser idoso. Afinal que critério usa-se para definir quem é idoso? A idade cronológica? As mudanças ocorridas na aparência física, como os cabelos brancos e as rugas na pele? Pessoas que já são aposentadas? Para Weineck apud Matsudo (2001), pesquisadores das áreas da ciência do esporte e da atividade física, o envelhecimento pode ser considerado uma soma das alterações biológicas, psicológicas e sociais que levam a uma redução gradual das capacidades de adaptação e do desempenho psicofísico do indivíduo. Como afirmam Neri e Cachioni (1999), a velhice e o envelhecimento são realidades heterogêneas, isso é, variam conforme os tempos históricos, as culturas e as subculturas, as classes sociais, as histórias de vidas pessoais, as condições educacionais, os estilos de vida, os gêneros, as profissões e as etnias, dentre outros elementos que conformam as trajetórias de vida dos indivíduos e dos grupos.

Para definir quem seriam os participantes do estudo, ou seja, os idosos utilizou-se o conceito da Organização Mundial da Saúde (OMS) que considera idosos aqueles que possuem 60 anos ou mais, para países em desenvolvimento, como o Brasil.

\section{Escolas participantes: estrutura, espaço físico e ambiente}

Nas quatro escolas com o programa de educação de jovens e adultos, as turmas com maior número de idosos matriculados e com frequência de participação foram da etapa um, também chamada em algumas escolas de totalidade um, que equivale ao primeiro e ao segundo ano do ensino fundamental, período destinado à alfabetização. Essa, aliás, é o principal objetivo de aprendizagem dos idosos: leitura e escrita. 
As turmas são formadas basicamente por adultos e idosos, há poucos adolescentes e jovens nesses espaços. A frequência na maioria das aulas, assim como na EJA é bem variável, e, na maioria das vezes, os idosos estavam em maior número na sala. $\mathrm{O}$ ambiente de sala de aula é calmo, tem pouco barulho e muita concentração. Como todas as turmas que fizeram parte do estudo são pequenas, no máximo dez alunos por aula, o silêncio prevalecia sobre as conversas entre colegas e também entre alunos e professores. Há um bom relacionamento entre os alunos, sendo que a maioria já se conhecia do ano anterior, pois já frequentavam a escola há mais de um ano. A relação da professora com os alunos idosos é muito amigável, e em determinadas aulas observadas, essa é a única pessoa com que alguns idosos estabelecem diálogo em sala.

A escola da região Norte, faz parte da rede estadual de ensino, dispoe de boa estrutura física e amplo espaço. No período noturno, ocorrem as aulas da EJA, com apenas uma turma da totalidade um e uma turma da totalidade dois, também há turmas de ensino regular do ensino fundamental e médio. $\mathrm{O}$ ambiente na escola era muito tranquilo, como eram os primeiros a chegar, pois estavam recuperando aula em função da greve, os alunos da EJA não se encontravam com os outros alunos da escola, um grande número de jovens e adolescentes. A professora da totalidade dois estava de licença médica, e, durante um período, as totalidades um e dois tiveram aula juntas, com a professora da totalidade um. Em todas as escolas o número de matriculados é muito maior do que número de alunos que frequentaram as aulas observadas.

A escola localizada na região Sul, o segundo local em que foram realizadas as observações, pertence à rede estadual de ensino, possui uma boa estrutura, é grande, bem movimentada e as salas de aula estão dispostas em pavilhões. No turno da noite funcionam aulas do ensino regular com turmas de ensino fundamental e médio, e também a EJA, que tem apenas duas turmas, as totalidades um e dois. A movimentação nessa escola é maior do que na anterior, há vários adolescentes e jovens, porém, nas duas turmas de EJA, a maioria são adultos e idosos. A turma, que tem seis idosos, três adultos e uma jovem, é bem entrosada, todos conversam entre si e com a professora. Há três níveis diferentes de aprendizagem na turma, uma idosa já deveria ter avançado para a totalidade seguinte, mas preferiu ficar na turma por mais algum tempo.

$\mathrm{Na}$ região Leste, fica a única escola pertencente à rede municipal de ensino. Essa tem uma pequena estrutura física, desenvolve apenas o ensino fundamental e no período noturno só há turmas de EJA, da etapa um à etapa quatro. Nessa escola há pouca movimentação e poucos alunos, o espaço-físico é pequeno e as salas de aulas que estão dispostas em dois andares, além das aulas de currículo também é oferecido aos alunos educação física e percussão. $\mathrm{O}$ ambiente é agradável e bem familiar, pois a maioria dos alunos e funcionários mora na região. A turma é formada por sete pessoas, desses, três com mais de 60 anos. Os outros alunos são todos adultos. Na região 
Leste os idosos estão mais engajados nas atividades da escola, todas as turmas desenvolvem várias atividades juntas, e por ser menor e com poucos alunos, o ambiente é mais familiar.

A escola da região Oeste pertence à rede estadual de ensino, e no período noturno tem somente turmas de EJA, da etapa um à etapa nove (que correspondem ao ensino fundamental e médio). A etapa um é dividida em etapa um A e etapa um B, sendo esta uma turma intermediária que prepara o aluno para a etapa dois. Escola grande, com bom número de alunos, principalmente adolescentes e jovens, há bastante movimentação. Possui um projeto, no qual em um dia da semana é realizada apenas aulas das disciplinas de artes, educação física, inglês e leitura. Essa escola destacou-se em relação às outras por desenvolver várias atividades fora da sala de aula, bem diferentes das tradicionais de ensino de leitura e de escrita, as quais foram observadas nas outras três escolas.

\section{Professores dos idosos na EJA}

Nas quatro turmas de alfabetização que fizeram parte do estudo, as professoras eram do gênero feminino, todas com formação em Pedagogia e algumas com pós-graduação. Entre as professoras, a questão que mais chamou a atenção pela semelhança das respostas foi sobre a metodologia para a aula com idosos, à qual todas afirmaram não ter nada específico, pois tentam sempre mesclar atividades tradicionais e diferenciadas, retirando da prática o que pode dar certo, adaptam materiais e exercícios, considerando também as necessidades dos educandos. Sobre a metodologia, Santos e Sá (2000) afirmam que não há no Brasil uma pedagogia definida para os idosos, e, sim, algumas técnicas de trabalho em um processo de aprendizagem que devem privilegiar o aluno como sujeito de seu próprio aprendizado, numa relação participativa entre professor e aluno.

De maneira geral, as professoras possuem um modo muito semelhante de trabalhar, pois como as turmas são pequenas, o atendimento ao aluno é individual, passando de classe em classe, para explicar e fazer correções, já que os exercícios são feitos especificamente para cada aluno. Essa, aliás, outra característica comum entre as escolas, exceto na instituição da região Oeste. O quadro-negro é pouco utilizado, pois como os alunos estão aprendendo a escrever o recurso mais usado pelas educadoras são as folhas prontas de exercícios.

Sobre a participação dos idosos em sala de aula todas as professoras afirmaram que ocorre de forma ativa, são eles que mais as apoiam, são os mais pontuais, interagem bastante, porém não gostam de enfrentar situações que precisam se expor, como levantar-se para escrever no quadro-negro ou falar pra toda a turma. Todas as educadoras afirmaram valorizar mais o diálogo após terem começado a trabalhar com idosos, considerando mais o lado pessoal e a experiência de vida dos educandos, e que às vezes é mais importante conversar e ouvi-los do que passar as atividades planejadas, ou seja, fazem do diálogo uma parte da aula. Para Sá (2004), o papel do professor é de suma importância e deve ultrapassar a mera transmissão 
de conteúdos, esse deve mediar, auxiliar ou facilitar o acesso do aluno ao conhecimento, ligando-o com sua experiência cotidiana, permitindo a análise crítica dessa experiência e a sua ultrapassagem no sentido da existência.

Os alunos idosos exigem do professor uma postura mais tradicional, calcada na educação que receberam de seus pais, de uma época em que tudo era imposto, e o professor, considerado superior por ser o detentor do conhecimento. Por esse motivo, os educandos não gostam muito de atividades diferenciadas, extrasala, e acreditam que "perdem tempo", pois querem mesmo é ficar em sala de aula e escrever no caderno. A professora da região Norte afirma que sentiu dificuldade em compreender essa questão, pois o que os alunos desejavam era diferente do modo como ela acreditava ser o melhor método de ensinar, conforme o relato abaixo:

[...] conversando com as minhas colegas, que já foram minhas colegas em escolas de EJA, eu vejo essa resistência mesmo de que aula boa pra eles é aula que enche o caderno e pra mim é uma coisa muito dolorosa porque não foi isso que eu aprendi na faculdade (PROFESSORA DA REGIÃO NORTE).

Apesar de perceberem que os idosos são persistentes para aprender, todas as educadoras ressaltaram na entrevista a importância de estar constantemente motivando os alunos, trabalhando a autoestima, criando estratégias, como dar muita atenção e elogiá-los bastante, para que eles não desistam.

A professora da região sul, que tinha a ajuda de uma estagiária em um dia da semana, afirmou ser muito importante a inserção dos idosos no ambiente escolar, e ressalta que dois alunos que tinham depressão, tornaram-se independentes dos remédios por terem vindo à escola, acredita que, com os estudos, o idoso passa a se sentir importante, valorizado, conhece pessoas e lugares diferentes. Essa ideia é confirmada por Cachioni (2003) que acredita que os programas educacionais devem possibilitar aos idosos uma maior relação com as outras gerações, exercitando sua capacidade de exigir seus direitos, e de autonomia de pensamento, como membros úteis da sociedade.

Um fato observado na escola da região oeste que chamou bastante atenção foi sobre a reclamação dos alunos em relação à atuação da professora. Os alunos não gostam do fato de a professora propor muitas atividades que não são do interesse dos educandos, como por exemplo, filmes, visitas em horário de aula e brincadeiras. No entanto, ela ressalta que faz isso, pois acredita que a maioria dos educandos da EJA está buscando convivência e socialização:

[...] é um trabalho bem gratificante, o resultado tu vê a longo prazo, é bem demorado, não é como a criança que te responde loguinho tu vai fazendo né, é bem demorado, tem que ter paciência, calma, mas é bem gratificante, porque são alunos tu vê ali na minha sala né, não tem problema de disciplina, eles estão ali porque querem e tem muitos assim que vem só pra viver, sabe conviver, fazer sua parte social [...] (PROFESSORA DA REGIÃO OESTE).

Both (2002) aponta algumas premissas importantes no que diz respeito aos princípios nas possibilidades da educação gerontológica: o educador deve 
possuir sensibilidade, necessitando de conhecimento sobre o desenvolvimento humano; o educador precisa ser um bom observador, a partir do aprofundado e constante estudo sobre as realidades vividas pelos mais velhos; o educador ter vontade/ação efetiva para resolver os problemas observados; a intervenção educacional depende de uma ação coesa e das parcerias de ações interdisciplinares; atenção sobre o cotidiano a todos envolvidos, e para tornar mais eficaz a educação gerontológica é preciso educar para o envelhecimento e a velhice.

\section{Idosos estudantes da EJA}

Os treze idosos que participaram da pesquisa, dez mulheres e três homens, têm idades que variam de 61 a 74 anos, apenas quatro desses são naturais de Santa Maria-RS, destacando que a maioria nasceu na zona rural de diferentes municípios. Sete idosos são casados e moram com seus companheiros, apenas uma idosa mora sozinha, oito são aposentados e das dez mulheres idosas, seis trabalharam e algumas trabalham até hoje como doméstica. Abaixo, para maior conhecimento dos sujeitos participantes do estudo segue na Tabela 2 informações dos idosos.

Tabela 2 - Informações dos idosos participantes do estudo

\begin{tabular}{|c|c|c|c|c|c|c|}
\hline $\begin{array}{l}\text { Região da } \\
\text { escola }\end{array}$ & Idosos & Idade & $\begin{array}{c}\text { Local de } \\
\text { nascimento }\end{array}$ & Estado civil & Profissão que exerceu & $\begin{array}{c}\text { Estudou na } \\
\text { infância }\end{array}$ \\
\hline \multirow{3}{*}{ NORTE } & $\mathrm{N} 1$ & 62 anos & São Gabriel & Casado & Auxiliar Veterinário & Sim \\
\hline & $\mathrm{N} 2$ & 67 anos & Uruguaiana & Viúva & Doméstica & Sim \\
\hline & N 3 & 74 anos & Santa Maria & Casada & Dona de casa & Sim \\
\hline \multirow{4}{*}{ SUL } & S 1 & 69 anos & Candelária & Casada & Dona de casa & Não \\
\hline & S 2 & 68 anos & Santa Maria & Solteira & Doméstica & Não \\
\hline & S 3 & 73 anos & Formigueiro & Viúva & Dona de casa & Não \\
\hline & S 4 & 65 anos & Santa Maria & Casada & Doméstica & Não \\
\hline \multirow{3}{*}{ LESTE } & L 1 & 68 anos & Formigueiro & Casado & Servente de obras & Sim \\
\hline & L 2 & 67 anos & Júlio de Castilhos & Solteira & Doméstica & Sim \\
\hline & L3 & 64 anos & Santa Maria & Divorciada & Servente de limpeza & Sim \\
\hline \multirow{3}{*}{ OESTE } & 01 & 69 anos & Bagé & $\begin{array}{l}\text { Casado só } \\
\text { no religioso }\end{array}$ & Operador de máquina & Não \\
\hline & $\mathrm{O} 2$ & 61 anos & Getúlio Vargas & Viúva & Doméstica & Não \\
\hline & O 3 & 63 anos & Ivorá & Casada & Doméstica & Não \\
\hline
\end{tabular}

Fonte: dados da pesquisa.

Um fato interessante encontrado nesta pesquisa é que todos os idosos entrevistados das escolas das regiões Norte e Leste haviam estudado quando crianças, e nenhum dos idosos das escolas das regiões Sul e Oeste chegou a frequentar uma escola na infância. Dos que já haviam estudado, a maioria teve 
de parar em função de ter que trabalhar ajudando os pais na lavoura, ou porque moravam no interior e não tinham como ir todos os dias na aula, em função da distância. Os que nunca tinham estudado, não tiveram oportunidade por residirem longe de alguma escola, ou devido aos pais não acreditarem na necessidade de estudar, não os colocando na escola.

Nas escolas da região Norte e Leste os idosos interagiam poucas vezes com os outros alunos, muitas vezes conversavam apenas com a professora, o ambiente na sala de aula era muito parecido. Nessas duas instituições, havia bastante silêncio e concentração. Já a interação nas turmas das escolas da região Sul e Oeste era maior, havia um bom relacionamento entre os colegas, faziam brincadeiras e piadas constantemente durante as aulas, principalmente na região Oeste, onde um dos idosos se destacou como o mais participativo e falante. Na região sul o clima de amizade entre os colegas era favorecido pelas dinâmicas de socialização propostas pela professora. Percebe-se, nas quatro turmas observadas, uma dependência dos idosos em relação à professora, requerendo atendimento individualizado, várias explicações da mesma atividade e confirmação de que estão certos para seguirem adiante.

Apesar de esses idosos terem procedências e histórias tão diferentes, os motivos que os levaram à escola têm muito em comum, eles buscam independência, autonomia e liberdade, condições que estão associadas ao ato de ler e escrever.

Alfabetizar-se, para esses educandos idosos, significa muito mais que aprender a ler e escrever, significa evitar constrangimentos ao ter que pedir para que alguém leia suas correspondências, muitas vezes confidenciais, significa deixar de perguntar sobre uma informação que sabem estar escrita no cartaz à frente, como o itinerário do ônibus e a indicação do banheiro feminino e masculino. Participar de um programa educacional para esses idosos significa buscar maior qualidade de vida e uma velhice bem-sucedida, ou seja, querem aproveitar bem o tempo que têm de vida.

A socialização também é um dos principais motivos que levou esses idosos a engajarem-se na EJA. A convivência com outras pessoas, que têm histórias diferentes do círculo habitual de amizades, as conversas, e até mesmo para não ficarem em casa sozinhos e sem atividade fazem com que esses participem e permaneçam na escola. Corroborando com Sá (2004) ao afirmar que o idoso quer tornar-se pessoa por meio de seus pares e dos que constituem o seu universo mais próximo. Para a autora, o idoso quer ser importante, mas também quer estar com, no sentido de comunhão, cooperação, compaixão, compreensão e complementação. Essa ideia pode ser evidenciada na fala dos idosos:

Eu vim pra estudar, porque arruma mais amizade, mais, como que se diz, abri mais a cabeça, a gente já ta mais descansado, fica aqui na parceria com os colegas, fica mais à vontade, porque fica só em casa, olhando aquela bobagem na televisão, também, eu não, não adianta (IDOSO, ESTUDANTE DA REGIÃO OESTE, 69 ANOS). 
[...] eu acho melhor ta no colégio do que ta em casa, em casa a gente fica muito, né, quando minha irmã vinha pro colégio, eu ficava "solita" em casa, né, ai me sentia tão sozinha, sem ninguém pra conversar com a gente, até a hora que ela chegava, e aqui não, aqui a gente vem junto e vai junto, aí chega em casa bem feliz [...] tá muito bom, to gostando (IDOSA, ESTUDANTE DAREGIÃO LESTE, 67 ANOS).

Para Valente (2001) as atividades educacionais para a terceira idade indicam que aprender está deixando de ser uma simples condição para manter posições atuais ou conseguir melhores salários e tornando-se, uma maneira de se divertir, de ocupar-se, de preencher o tempo e de estar em sintonia com a atualidade. Segundo D'Alencar (2002) o idoso ao procurar um programa de educação não o faz pela necessidade de competir, a sua busca não tem sido o diploma e, sim, o crescimento pessoal e a capacidade de situar-se na realidade a que pertence. Apesar de a maioria dos idosos terem confirmado as ideias dos autores acima, um educando da região Leste afirmou ter como objetivo estudar para qualificar-se para o mercado de trabalho:

É a meta minha é aprender, né, pegar uma, pegar uma profissão, uma coisa, fica mais fácil, né, o cara aprendendo a ler o cara sabe se defender melhor (IDOSO, ESTUDANTE DA REGIÃO LESTE, 68 ANOS).

Entre as dificuldades encontradas pelos estudantes idosos destacam-se às questões relacionadas à aprendizagem, alguns reclamam sobre a demora em aprender, muitas vezes associando à idade. A falta de memória, o cansaço, e até a presença de algumas doenças foram descritas como fatores que atrapalham na aprendizagem. Stella (2004) afirma que a memória de trabalho ou memória operacional e a memória de reconhecimento mantêm-se praticamente intacta no idoso ou apresenta discreto declínio, porém, o idoso pode apresentar certa dificuldade de se lembrar conteúdos recentemente aprendidos, sobretudo quando esses se referem a situações episódicas e isoladas.

Contudo, apesar do envelhecimento apresentar-se como uma barreira, também é encarado como uma forma de superação entre os idosos, pois mesmo com presença de doenças, ou sintomas da velhice, a participação desses na escola é encarada com persistência:

[...] é só aprender um pouquinho mais, pro gasto, entendeu, pra mim, né, não, não tem, tem gente que ainda sonha com alguma outra coisa, não, eu não tem, eu acho, além de eu me achar bastante velha e doente, né, eu tenho muito problema, eu vou assim, porque eu tenho muita força de vontade (IDOSA, ESTUDANTE DAREGIÃO SUL, 73 ANOS).

A maioria dos idosos já estava na escola há mais de um ano, alguns até foram orientados pela professora para que avançassem para a etapa seguinte, mas preferiram continuar na turma, por causa do bom relacionamento com colegas e a professora, e também porque sentem-se inseguros em mudar para uma nova etapa, com novos colegas e com conteúdo mais complexo. Eles temem não conseguir acompanhar a turma $\mathrm{e}$ preferem continuar no grupo em que estão. Uma idosa da região Norte avançou para a etapa dois, frequentou um tempo, mas pediu para retornar à antiga sala, pois sentiu que não estava aprendendo como os seus colegas: 
[...] eu tava na turma do dois, né, mas eu tava muito, os outros sabiam mais do que eu, daí eu pedi pra passar pra outra turma (IDOSA, ESTUDANTE DA REGIÃO NORTE, 74 ANOS).

Quando perguntados se sentiram alguma mudança em suas vidas após terem se inserido na escola apenas duas idosas afirmaram não ter percebido nada, porém, os outros 11 idosos ressaltaram ter sentido muitas mudanças. A segurança adquirida após terem aprendido a ler destaca-se como uma das principais, com isso aumentou também a autoestima dessas pessoas, que se sentiam incapazes de enfrentar situações e de conversar com alguém que julgavam ser superior por serem alfabetizados. Outra mudança foi a independência que ganharam em poder realizar suas atividades sozinhos, sem necessitar de ajuda dos outros, o que causava muitos constrangimentos.

Na fala de uma idosa também reflete a mudança que destaca ter encontrado na amizade que construiu na escola:

[...] muita mudança, muito, mesmo por as amizade, né, as amiga, os colegas que a gente às vezes pega uns colega muito poderosos, que dão uma força pra gente que eu vo te dizer, eu mesmo quando eu andei doente lá, essa minha colega, eu quero muito bem ela, essa minha colega que me levantava, eu queria cair, vamo levanta pra aula [...] (IDOSA, ESTUDANTE DA REGIÃO OESTE, 61 ANOS).

O sentimento de pertencimento também foi instituído a partir da inserção na EJA, a sensação de ser parte de um grupo, de fazer novas amizades, de participar de atividades variadas, e até mesmo o estabelecimento de um compromisso fez com que esses idosos passassem a se sentir úteis e membros da sociedade. Como destaca Del Pozzo (2001), o contato com outros idosos em idênticas situações permite que ele perceba que todos têm dificuldades, mas, apesar disso, continuam firmes na luta. Ele troca os antigos muros isoladores por amplas e luminosas janelas, pois agora ele quer ver o mundo, há novas possibilidades, surgem novos amigos, companheiros de jornada e de trincheira.

Outra mudança muito ressaltada pelos educandos foi pelo fato de sentirem-se mais felizes e menos solitários ao frequentar a aula, conhecer novas pessoas, conversar com os colegas e os professores. Quando ficavam em casa não tinham o que fazer, com quem conversar, ocupando a cabeça com pensamentos negativos, agora afirmaram ter encontrado um entretenimento, uma ocupação, que além de ter trazido muitos benefícios através da aprendizagem, também arrumaram novos amigos, como falam Palma e Cachioni (2002), a inclusão do idoso em um programa educativo não é apenas uma oportunidade de reciclagem intelectual, mas, sim, uma possibilidade de dialogar e de participar com seus iguais na construção do seu próprio processo formativo.

\section{Conclusão}

Após participar um pouco do cotidiano de escolas de quatro regiões distintas da cidade, com suas especificidades, processos históricos variados, personagens e histórias diferentes, algumas questões podem ser relatadas como semelhantes, pois de certa maneira possuem muito em comum. Primeiramente, é destacada a organização e a estrutura de todas as ins- 
tituições, independente da rede de ensino, pois se apresentaram abertas e a favor da pesquisa colaborando desde o início para sua exequibilidade. Pode-se afirmar, também, que os idosos estão presentes nos ambientes escolares, não apenas pelo número significativo que se encontram nas salas de aulas, mas pela efetiva busca de um envelhecer mais digno.

Para esses idosos em que a educação na infância foi negada, a aprendizagem da escrita e da leitura não objetiva apenas a alfabetização por si própria, mas, sim, à liberdade de poder entender o mundo, de compreender o seu contexto e de questionar tantas injustiças. O que moveu esses educandos à escola foi a necessidade de não depender mais dos outros para realizar atividades básicas, para poderem, enfim, tirar a venda e desatar as amarras que os fazem cegos e prisioneiros do analfabetismo.

Acerca da preparação dos educadores para atuarem na EJA, cujo universo é bastante heterogêneo, e que, atualmente, está enfrentado a participação não só de jovens e adultos, é uma questão bastante importante, no que diz respeito a conhecer esse novo aluno, $o$ idoso. Nenhum dos quatro professores entrevistados afirmou ter tido preparação específica sobre o envelhecimento, e dependem da experiência que têm em alfabetizar crianças para realizarem seu trabalho, o que acaba, muitas vezes, fazendo com que o educando não se sinta parte do processo ensino-aprendizagem.

Nesse contexto destacamos que deveria existir maior parceria entre as universidades e as instituições de educação básica, no sentido de que a primeira faça da pesquisa um instrumento para melhorar a qualidade de intervenção nas escolas, assim, a universidade cumpre sua função social de adequar as ofertas acadêmicas às demandas sociais, e consequentemente, haja uma educação de qualidade, a todos os segmentos da sociedade, independente de idade, cor, religião e status social.

A participação do idoso na escola é um primeiro passo para uma tomada de consciência de um ser que cresceu e desenvolveu-se sendo um mero expectador de sua própria vida. Sua inserção na educação é o início de uma caminhada que o faz colocar-se como ser histórico, pensante, deixando o papel de ator e passando ser autor de sua história.

\section{Education and aging: the realities of the education of youth and adults}

\section{Abstract}

The present study aimed to analyze the participation of older people in education programs for youth and adults in Santa Maria / RS, in order to know the motives of the elderly who returned or started to study, to know which the elderly student feel about it; know the perception of their teachers and to analyze the participation of the elderly in the classroom. So was developed a qualitative and descriptive study, using interviews and observations with the elderly and their teachers. The participants were 4 teachers and 13 seniors. The results showed that the reasons that led the elderly to the school was the seek of independence, autonomy and freedom, conditions that are associated with the act of reading and writing. Socialization is also one of the main reasons that led these senior citizens to engage in EJA. 
About teachers it was found that none of the four said they had special training on aging, or to work with elderly, basing their practice on past experience. Therefore highlights the importance of rapprochement between university and school in order to prepare these teachers for this reality. Thus the effective participation of the elderly in school can be a first step towards an awareness of a being who has grown and developed as mere spectator of his own life.

Keywords: Education; Aging; School.

\section{Referências}

ACOSTA, M. A. F. Getting old in the city: a study on groups of physical activities for elderly people in Santa Maria/RS. The FIEP Bulletin, Foz do Iguaçu, v. 77, n. special, p. 625-628, Jan. 2007.

D'ALENCAR, R. S. Ensinar a viver, ensinar a envelhecer: desafios para a educação de idosos. Revista Estudos Interdisciplinares sobre Envelhecimento, Porto Alegre, v. 4, n. 4, p. 61-83, 2002.

BOTH, A. Possibilidades e limites de uma educação para idosos: metodologias. In: ENCONTRO IBERO-AMERICANO: A INTERVENÇÃO EDUCATIVA NA VELHICE DESDE A PERSPECTIVA DE UMA PEDAGOGIA SOCIAL, 1, 2002, Caxias do Sul. Anais... Caxias do Sul: UCS, 2002. p. 70-72.

CACHIONI, M. Quem educa os idosos? Um estudo sobre os professores de Universidades da Terceira Idade. Campinas-SP: Editora Alínea, 2003.

CHIZZOTTI, A. Pesquisa em Ciências Humanas e Sociais. São Paulo: Cortez, 2000.

DEL POZZO, O. Os grupos de Terceira Idade: Comentários e reflexões. Revista A Terceira Idade. São Paulo, v. 12, n. 22, p. 2, jul. 2001.

MATSUDO, S. Envelhecimento e Atividade Física. Londrina: Midiograf, 2001.
NERI, A. L., CACHIONI, M. Velhice bem-sucedida e educação. In: NERI, A. L.; DEBERT, G. G. (Orgs.). Velhice e Sociedade. Campinas-SP: Papirus, 1999, p. 113-140.

PALMA, L. S.; CACHIONI, M. Educação Permanente: perspectiva para o trabalho educacional com o adulto maduro e com o idoso. In: FREITAS, E. V. (Orgs.) et al. Tratado de Geriatria e Gerontologia, Rio de Janeiro: Guanabara Koogan, 2002, p. 1101-1121.

SÁ, J. L. M. Educação e envelhecimento. In: PY, L. (Org.). Tempo de Envelhecer: percursos e dimensões psicossociais. Rio de Janeiro: NAU Editora, 2004, p. 201-232.

SANTOS, A. T.; SÁ, M. A. A. S. De volta às aulas: ensino e aprendizagem na terceira idade. In: NERI, A. L.; FREIRE, S. A. (Orgs.). $E$ por falar em boa velhice. Campinas-SP: Papirus, 2000. p. 91-100.

STELLA, F. Funções cognitivas e envelhecimento. In: PY, L. (Org.). Tempo de Envelhecer: percursos e dimensões psicossociais. Rio de Janeiro: NAU Editora, 2004.

VALENTE, J. A. Aprendizagem Continuada ao Longo as Vida: o exemplo da terceira idade. In: KACHAR, V. (Org.). Longevidade: um novo desafio para a educação. São Paulo: Cortez, 2001. p. 23-35. 